\title{
Association of maternal iodine intake with congenital hypothyroidism
}

P. GOPIKA ${ }^{1 \dagger *}$, M. SREELAKSHMI ${ }^{1 \dagger}$, SAJAL NALWAYA ${ }^{1 \dagger}$, SARITA JANGRA BHYAN ${ }^{1}$

College of Pharmacy, Teerthanker Mahaveer University, Moradabad, Uttar Pradesh 244001, India. ${ }^{1}$

* Address for correspondence: College of Pharmacy, Teerthanker Mahaveer University, Moradabad, Uttar Pradesh - 244001, India Email ID: gopikanair208@gmail.com

${ }^{\dagger}$ All the three authors contributed equally to the manuscript. 


\section{Association of maternal iodine intake with congenital hypothyroidism}

The iodine intake in a pregnant woman has been closely correlated with development of transient congenital hypothyroidism which leads to decline in neurocognitive abilities of the child later in life as the effects are very subtle at birth. Both low and excess ingestion of iodine has been found to contribute to this cause, although iodine deficiency is more commonly observed in women of underdeveloped nations. It poses risks not only to the foetus but also to the mother leading to obstetric complications such as still birth and spontaneous abortions. It can be prevented using WHO recommended daily iodine supplementation in deficient regions or decreasing the excess load in groups exposed to high iodine. Programmes designed to screen the new-born at birth can also help in improving the quality of life of the child. The deficient iodine condition is managed by administration of levothyroxine in dosage range of 10$15 \mathrm{mcg} / \mathrm{kg} / \mathrm{day}$. Generally, the prognosis of infants starting treatment early in life have a better neurocognitive outcome as compared to the treated infants late age at a later age. Avoidance of agents causing iodine exposure has resulted in decrease in the abnormal thyroid function levels.

Keywords: congenital hypothyroidism; transient; iodine deficiency; iodine excess; pregnancy; supplementation 


\section{Congenital Hypothyroidism - Introduction}

Congenital hypothyroidism is an endocrine disorder which interferes with the proper growth, metabolism and brain development due to the deficiency of thyroid hormone at the time of birth [1]. The ratio of its incidence is $1: 2,000$ to $1: 4,000$ births approximately [2]. The clinical findings of congenital hypothyroidism are often covert in nature and develop gradually over time. However, some of the classical findings are facial puffiness, large tongue, lethargy, hypotonia, umbilical hernia [3]. The NBS programme for the early detection and prevention of complications from congenital hypothyroidism started in 1974 was successful in lowering the disease burden worldwide but the implementation of such programs still remains complex in developing countries like India due the large portion of home births and lack of patient follow up after discharge from the hospital [4,5].

\section{Classification of Congenital hypothyroidism and its aetiology.}

Congenital hypothyroidism can be permanent or transient in nature. Permanent congenital hypothyroidism is deficiency of thyroid hormone permanently and requires lifelong management whereas; Transient congenital hypothyroidism is the temporary deficiency of thyroid hormone observed at birth which resolves within few months of birth with proper medical management [6]. Permanent Congenital hypothyroidism is further classified into primary, secondary and peripheral congenital hypothyroidism. Some forms of congenital hypothyroidism affect other organs in the body is called syndromic hypothyroidism [2]. [Table 1. near here] 


\section{Physiology of iodine in pregnancy.}

Iodine is an essential nutrient needed for the synthesis of thyroid hormones in our human body. It is absorbed in the stomach and the duodenum (97\%) from the food, water and other supplements ingested. The iodine which is not taken by the thyroid gland is excreted predominantly through the urine (90\%) and only $1 \%$ is excreted through faeces [9].The physiological requirement of iodine is increased by $50 \%$ during pregnancy and it is generally met by the $15-20 \mathrm{mg}$ iodine stored in the thyroid gland of women residing in the iodine sufficient regions [10-12]. The pregnant women residing in the iodine deficient regions possess high maternal and foetal health risks as there is increased decline in the maternal iodine levels due to the increased renal clearance and placental metabolism of iodine which brings about higher demand of iodine in pregnancy [13]. The vascularisation of thyroid gland during pregnancy, stimulation of thyroid by the Beta-Human chorionic gonadotropin $(\propto-\mathrm{HCG})$ which is a structural analogue of TSH and increased circulating thyroid binding globulin (TBG) due to oestrogen stimulation are responsible for an increased production of thyroid hormone which is essential for the foetal brain development and growth during early pregnancy [14-16], and the insufficiency of iodine in the maternal during this stage contributes towards risk of congenital hypothyroidism in the child at the time of birth.

\section{Epidemiology of iodine deficiency.}

WHO estimates that around 2 billion people fall under the iodine deficient population. The highest percentage of iodine deficiency in the general population has been reported in Europe with about 52\% followed by Eastern Mediterranean with 47.2\%, Africa with 41.5\%, Southeast Asia with 30.0\% and Western Pacific with 21.2\%. The lowest iodine deficiency was reported in Americas with 11.0\% [17]. 


\section{Iodine deficiency and its effects on maternal and child health}

In the initial weeks of development, the mother is the only source of thyroid hormones for the fetus. Although the placenta performs the function of a barrier to avoid the markedly increased $\mathrm{T}_{4}\left(\mathrm{fT}_{4}\right)$ and $\mathrm{T}_{3}$ levels to reach the fetus, subsequent to $\sim 4$ weeks of conceiving, hormones are found in the cavities of embryo $[18,19]$. It is from $\sim 8-9$ weeks of gestation that the fetal brain develops thyroid hormones receptors and begin functioning only from 15-17 weeks of gestation. At this time, it depends on the supply of maternal iodine to sustain the production of thyroid hormone during the rest of gravidity $[19,20]$.

Thyroid hormones perform essential function in fetal brain growth and development and this is a reflection of the maternal iodine status $[21,22]$. Deficiency or excess of iodine has consequences on the health of both mother and child.

\section{Effects on obstetric health}

Iodine deficiency exhibits itself most prominently as subclinical or overt hypothyroidism in women however several other consequences on reproduction are also observed [23]. Stimulation of TSH in iodine deficient pregnant women can also cause goiter $[24,25]$. Studies from Europe have found that during the gestational period, the thyroid volume in iodine deficient women increases by $25 \%$ as compared to that of 10 $15 \%$ in iodine sufficient women [26-29]. Animal models have suggested a negative effect on fertility. Ewes, deficient in iodine, had shown reproductive failure in $21 \%$ of cases as compared to $4.3 \%$ of the controls [30]. Epidemiological data from various geographical regions demonstrate that there is an amplified risk in iodine deficient women to have undesirable obstetric effects such as spontaneous abortions, stillbirth, premature birth and neonatal deaths [31-33]. 


\section{Effects on child health and development}

Due to iodine deficiency, thyroid hormone production is hampered. This inadequacy results in various growth and development diseases, together called as iodine deficiency disorders (IDD) [34]. Moderate to severe iodine deficiency causes maternal hypothyroxinemia which harms the fetal brain development in form of disruption of neuronal migration in early pregnancy and later intensified due to fetal hypothyroidism [35,36]. Major neonatal abnormalities include congenital hypothyroidism, decreased intelligence, and neurological cretinism $[37,38]$.

Severe iodine deficiency has been associated with the cognition ability of the child. Results from a meta-analysis of data showed that, on an average, intelligence quotient (IQ) score of 12.5 points were lesser in iodine deficient children than the iodine sufficient children [39].

Although mild to moderate iodine deficiency effects on child is uncertain, but results from a study that evaluated children aged 7-9 years of euthyroid women have IQ of 7 points higher than the children of women who had mild TSH elevation in their second trimester [40]. Another study showed the difference in psychomotor scores of 10month-old infants of women with hypothyroxinemia when compared to infants of euthyroid women with the former having lower scores [41].

Another serious disease is cretinism which are of mainly two types, i.e., neurological and myxedematous, both diverse in their manifestation of features. (Figure 1 near here) 


\section{Iodine supplementation.}

Iodine excretion through renal pathway increases with increase in glomerular filtration rate by $30 \%$ to $50 \%$ during pregnancy $[42,29]$. Due to the physiological changes during pregnancy such as elevated iodide renal clearance, increased thyroid hormone production and fetal iodine requirements, dietary iodine consumption also needs to be increased to meet the demands [29]. It is known that both maternal and fetal disorders secondary to IDD are preventable diseases, and justifies the consideration of iodine supplementation during pregnancy and breast feeding.

World Health organization (WHO) recommends use of iodized salt is the mainstay therapy in treating iodine deficiencies and supplementation only in prone groups from severely deficient regions where salt iodization is not achievable. Suggested dosages for daily iodine intake indicates higher requirements for pregnant and lactating women as compared to non-pregnant women of child bearing age [39]. (Table 2 near here)

Several studies have established the effectiveness of iodine supplementation for iodine deficient pregnant women in reducing or eliminating the risks of neurocognitive dysfunction in offspring [43-47]. 


\section{Role of maternal iodine intake in developing congenital hypothyroidism and its management}

Iodine has a major role to play in the development of transient congenital hypothyroidism in new-born. Both iodine deficiency and iodine excess are known to contribute towards its cause.

(1) Endemic Iodine Deficiency: Globally, iodine deficiency is the most common cause of transient hypothyroidism [48-50]. Europe and North America are deficient in iodine stores and transient congenital hypothyroidism due to iodine deficiency is very commonly noted here. Iodine makes up for $50-60 \%$ of the thyroid hormones. The low in utero thyroidal stores, immaturity of HPT axis and inability to covert T4 to T3 put preterm babies at an increased risk. India is now an iodine sufficient country but proper data regarding the burden of congenital hypothyroidism is lacking [51-54]. Management is usually done by administering levothyroxine in dosage range of $10-15 \mathrm{mcg} / \mathrm{kg} / \mathrm{day}$ until thyroid function parameters become normal [55].

(2) Iodine Excess: The exposure of drugs such as amiodarone, iodine antiseptics, contrasts media or supplements in mothers during pregnancy or neonates cause transient congenital hypothyroidism [56-58]. Unlike adults, babies cannot escape from the acute Wolff - Chaikoff effect in the case of iodine load due to the inability of the thyroid gland to regulate the iodine uptake, increased absorption of iodine by the skin and decreased renal clearance and thus develop iodine induced hypothyroidism. Preterm babies possess a higher risk in developing the disease. [59-61]. The new-born, exposed to high iodine quantity, will present low T4 and high TSH concentrations, generally after 2 to 3 days of age. Several studies have demonstrated that excessive iodine transfer, either through placenta or breast milk, can cause neonatal hypothyroidism [62- 
65]. It can be managed with avoidance of agents causing the iodine exposure until the thyroid function levels fall back within the normal range.

\section{CONCLUSION}

Undoubtedly, low levels of iodine are common in pregnant women and this can result in iodine deficiency disorders hampering the neurocognitive abilities of the child. The evidence for possible functions of iodine in childhood, fetal neural development and obstetric health need to be acknowledged so that our knowledge and understanding is increased. Supplementation, as recommended by international organizations, with 250 $\mu \mathrm{g}$ iodine daily during pregnancy and lactation is justified. Iodine deficiency disorders are preventable and thus early detection and timely management will ensure lowering the burden caused by these diseases. Feasible approaches to ensure adequate supplementation, compliance and screening should be considered for implementation in all countries including the developing nations. However, several case reports have also suggested that exceeding the safe upper limit of daily supplementation dose, also pose a risk to the fetus and thus creation of personalized dosage regimen is emphasized. 
Funding details: Not applicable.

Disclosure of interest: The authors report no conflict of interest. 


\section{REFERENCES}

(1) Dei-Tutu SA, Manful A, Heimburger DC, et al. Correlating maternal iodine status with neonatal thyroid function in two hospital populations in Ghana: A multicenter cross- sectional pilot study. BMC Pediatr 2020; 20(1):26.

(2) Rastogi MV, LaFranchi SH. Congenital hypothyroidism. Orphanet J Rare Dis.2010; 5:17.

(3) Segni M. Congenital Hypothyroidism. [Updated 2019 Aug 11]. In: Feingold KR, Anawalt B, Boyce A, et al., editors. Endotext [Internet]. South Dartmouth (MA): MDText.com, Inc.; 2000-. Available from: https://www.ncbi.nlm.nih.gov/books/NBK279004/

(4) Park SM, Chatterjee VKK. Genetics of congenital hypothyroidism. J Med Genet. 2005;42(5):379.

(5) Unnikrishnan AG, Vyas U. Congenital hypothyroidism - An Indian perspective. Thyroid Research and Practice. 2017;14(3):99.

(6) American Academy of Pediatrics, Rose SR; Section on Endocrinology and Committee on Genetics, American Thyroid Association, et al. Update of new-born screening and therapy for congenital hypothyroidism. Pediatrics. 2006;117(6):2290-2303.

(7) Agrawal P, Philip R, Saran S, et al. Congenital hypothyroidism. Indian J Endocrinol Metab. 2015;19(2):221-227.

(8) Bhavani N. Transient congenital hypothyroidism. Indian J Endocrinol Metab. 2011;15(Suppl 2):S117-S120.

(9) Zimmermann MB. Iodine Deficiency. Endocr Rev. 2009;30(4):376-408. 
(10) Elnagar B, Eltom A, Wide L, Gebre-Medhin M, et al. Iodine status, thyroid function and pregnancy: study of Swedish and Sudanese women. Eur J Clin Nutr. 1998;52(5):351-355.

(11) Glinoer D. The regulation of thyroid function in pregnancy: pathways of Endocrine adaptation from physiology to pathology. Endocr Rev. 1997;18(3):404-433.

(12) Zimmermann MB. Iodine deficiency in pregnancy and the effects of maternal iodine supplementation on the offspring: a review. Am J Clin Nutr. 2009;89(2):668S-672S.

(13) Lazarus JH. The importance of iodine in public health. Environ Geochem Health. 2015;37(4):605-618.

(14) Soldin OP, Tractenberg RE, Hollowell JG, et al. Trimester- specific changes in maternal thyroid hormone, thyrotropin, and thyroglobulin concentrations during gestation: trends and associations across trimesters in iodine sufficiency. Thyroid. 2004;14(12):1084-1090.

(15) Casey BM, Leveno KJ. Thyroid disease in pregnancy. Obstet Gynecol. 2006;108(5):1283-1292.

(16) Skjöldebrand L, Brundin J, Carlström A, Pettersson T. Thyroid associated components in serum during normal pregnancy. Acta Endocrinol (Copenh). 1982;100(4):504-511.

(17) de Benoist B, McLean E, Andersson M, Rogers L. Iodine deficiency in 2007: global progress since 2003. Food Nutr Bull. 2008;29(3):195-202.

(18) Morreale de EG, Obregon MJ, Escobar del RF. Maternal thyroid hormones early in pregnancy and fetal brain development. Best Pract. Res. Clin. Endocrinol. Metab. 2004;18:225-248. 
(19) Williams G.R. Neurodevelopmental and neurophysiological actions of thyroid hormones. J. Neuroendocrinol. 2008;20:784-794.

(20) Delange F. Iodine requirements during pregnancy, lactation and the neonatal period and indicators of optimal iodine nutrition. Public Health Nutr. 2007;10:1571-1580.

(21) Prashant T, Yashwant R, Malvika M. Systematic review on association between iodine level during pregnancy and its outcomes. Int J Health Sci Res. 2018;8(10):269-279.

(22) Özon A, Tekin N, Şıklar Z, et al. Neonatal effects of thyroid diseases in pregnancy and approach to the infant with increased TSH: Turkish Neonatal and Pediatric Endocrinology and Diabetes Societies consensus report. Turk Pediatri Ars. 2018; 53(Suppl 1): S209-S223.

(23) Dillon J. C, MilliezJ. Reproductive failure in women living in iodine deficient areas of West Africa. BJOG. 2000; 107(5):631-636.

(24) Yoshimura M, Hershman JM . Thyrotropic action of human chorionic gonadotropin. Thyroid. 1995;5:425-434.

(25) Glinoer D, de Nayer P, Bourdoux P et al. Regulation of maternal thyroid during pregnancy. J Clin Endocrinol Metab. 1990;71:276-287.

(26) Smyth PPA, Hetherton AM, Ryan R, O’Herlihy C . Alterations in iodine status and thyroid volume in pregnancy. In: Beckers C, Reinwein D (eds) The Thyroid and Pregnancy. 1991:55- 58.

(27) Brander A, Kivisaari L . Ultrasonography of the thyroid during pregnancy. J Clin Ultrasound. 1989; 17: 403-406.

(28) Rasmussen NG, Hornnes PJ, Hegedus L . Ultrasonographically determined thyroid size in pregnancy and post partum: the goitrogenic effect of 
pregnancy. Am J Obstet Gynecol. 1989; 160: 1216-1220.

(29) Glinoer D . The importance of iodine nutrition during pregnancy. Public Health Nutr. 2007; 10: 1542-1546.

(30) McMichael AJ, Potter JD, Hetzel B. Iodine deficiency, thyroid function and reproductive failure. In: JB Standbury, B Hetzel, editors. Endemic Goitre and Cretinism. Iodine Nutrition in Health and Disease.1980: 445460.

(31) Pharoah P, Buttfield I, Hetzel B. Neurologic damage to the foetus resulting from severe iodine deficiency during pregnancy. Lancet. 1971;1:308-310.

(32) Thilly C, Delange F, Standbury JB. Epidemiologic surveys in endemic goitre and cretinism. In: JB Standbury, B Hetzel, editors. Endemic Goitre and Cretinism. 1980:157- 179.

(33) Kochupillai N, Ramalingaswami V, Standbury JB. The present status of endemic goitre as a problem of public health: Southeast Asia. In: JB Standbury, B Hetzel, editors. Endemic Goitre and Endemic Cretinism. 1980:101- 121 .

(34) Zimmermann MB, Jooste PL, Pandav CS. Iodine-deficiency disorders. Lancet. 2008;372(9645):1251-1262

(35) Skeaff SA. Iodine deficiency in pregnancy: the effect on neurodevelopment in the child. Nutrients. 2011;3(2):265-273.

(36) Zoeller TR, Dowling AL, Herzig CT et al. Thyroid hormone, brain development, and the environment. Environ Health Perspect. 2002; 110: $355-361$.

(37) World Health Organization. Iodine Deficiency in Europe: A Continuing Public Health Problem. Geneva: World Health Organization, UNICEF: 
2007. Available at:

http://www.iccidd.org/cm data/2007 Andersson Iodine Deficiency in Europe W

HO.pdf. Accessed June21, 2020.

(38) World Health Organization, United Nations Children's Fund, and International Council for the Control of Iodine Deficiency

Disorders, Assessment of Iodine Deficiency Disorders and Monitoring their Elimination, WHO, Geneva, Switzerland, 3rd edition, 2007.

(39) M. Qian, D. Wang, W. E. Watkins et al., "The effects of iodine on intelligence in children: a meta-anylsis of studies conducted in China," Asia Pacific Journal of Clinical Nutrition. 2005;14(1): 32-42.

(40) Haddow JE, Palomake GE, Allan WC et al. Maternal thyroid deficiency during pregnancy and subsequent neuropsychological development of the child. N Engl J Med. 1999; 341: 549- 255.

(41) Pop VJ, Kuijpens Jl, van Baar AL et al. Low maternal free thyroxine conentrations during early pregnancy are associated with impaired psychomotor development in infancy. Clin Endocrinol. 1999;50: 147-148.

(42) Wayne EJ, Koutras DA, Alexander WD. Excretion of iodine. In : Clinical aspects of iodine metabolism. Philadelphia: Oxford, Blackwell; 1964.; p. 73-83.

(43) Velasco I, Carreira M, Santiago P et al. Effect of iodine prophylaxis during pregnancy on neurocognitive development of children during the first two years of life. J Clin Endocrinol Metab. 2009;94:3234-3241.

(44) Berbel P, Mestre JL., Santamaria A et al. Delayed neurobehavioral development in children born to pregnant women with mild hypothyroxinemia during the first month of gestation: the importance of 
early iodine supplementation. Thyroid. 2009;19:511-519

(45) Murcia M, Rebagliato M, Iniguez C et al. Effect of iodine supplementation during pregnancy on infant neurodevelopment at 1 year of age. Am $\mathbf{J}$ Epidemiol. 2011;173:804-812.

(46) Pharoah PO, Buttfield IH, Hetzel BS. Neurological damage to the fetus resulting from severe iodine deficiency during pregnancy. Lancet. 1971;1(7694):308-10

(47) Chen ZP, Hetzel BS. Cretinism revisited. Best Pract Res Clin Endocrinol Metab. 2010;24(1):39-50.

(48) Ares S, Quero J, Duran S et al. Iodine content of infant formulas and iodine intake of premature babies: high risk of iodine deficiency. Arch Dis Child. 1994;71(3):F184-F191

(49) Ares S, Escobar-Morreale HF, Quero J et al. Neonatal hypothyroxinemia: effects of iodine intake and premature birth. J Clin Endocrinol Metab. 1997;82(6): $1704-1712$

(50) Ares S, Quero J, Morreale de Escobar G. Neonatal iodine deficiency: clinical aspects. J Pediatr Endocrinol Metab. 2005;18(suppl 1):1257-1264

(51) Soldin OP, Tractenberg RE, Hollowell JG, et al. Trimester- specific changes in maternal thyroid hormone, thyrotropin, and thyroglobulin concentrations during gestation: trends and associations across trimesters in iodine sufficiency. Thyroid. 2004;14(12):1084-1090.

(52) Casey BM, Leveno KJ. Thyroid disease in pregnancy. Obstet Gynecol. 2006;108(5):1283-1292.

(53) Skjöldebrand L, Brundin J, Carlström A, Pettersson T. Thyroid associated components in serum during normal pregnancy. Acta Endocrinol (Copenh). 
1982;100(4):504-511.

(54) Gaudino R, Garel C, Czernichow P, et al. Proportion of various types of thyroid disorders among newborns with congenital hypothyroidism and normally located gland: a regional cohort study. Clin Endocrinol (Oxf). 2005;62(4):444-448.

(55) Selva KA, Mandel SH, Rien L, Sesser D, Miyahira R, Skeels M, Nelson JC, Lafranchi SH: Initial treatment dose of L-thyroxine in congenital hypothyroidism. JPediatr. 2002, 141 (6):786-792.

(56) Delange F, Dalhem A, Bourdoux P, et al. Increased risk of primary hypothyroidism in preterm infants. J Pediatr. 1984;105(3):462-469.

(57) Delange F. Neonatal screening for congenital hypothyroidism: results and perspectives. Horm Res. 1997;48(2):51-61.

(58) Toteja GS, Singh P, Dhillon BS, Saxena BN. Iodine deficiency disorders in 15 districts of India. Indian J Pediatr. 2004;71(1):25-28.

(59) Bartalena L, Bogazzi F, Braverman LE, Martino E. Effects of amiodarone administration during pregnancy on neonatal thyroid function and subsequent neurodevelopment. J Endocrinol Invest. 2001;24(2):116-130.

(60) Lomenick JP, Jackson WA, Backeljauw PF. Amiodarone-induced neonatal hypothyroidism: a unique form of transient early-onset hypothyroidism. $\mathbf{J}$ Perinatol. 2004;24(6):397-399.

(61) Pearce, E. Monitoring and effects of iodine deficiency in pregnancy: still an unsolved problem?. Eur J Clin Nutr. 2013;67:481-484.

(62) Nishiyama S, Mikeda T, Okada T et al. Transient hypothyroidism or persistent hyperthyrotropinemia in neonates born to mothers with excessive iodine intake. Thyroid. 2004;14:1077-83 
(63) Carswell F, Kerr MM, Hutchison JH. Congenital goitre and hypothyroidism produced by maternal ingestion of iodides. Lancet. 1970;1:1241-3.

(64) Markou K, Georgopoulos N, Kyriazopoulou V et al. Iodine-induced hypothyroidism. Thyroid. 2001;11:501-10.

(65) Leung AM, Pearce EN, Hamilton T, He X, Pino S, Merewood A, et al. Colostrum iodine and perchlorate concentrations in Boston-area women: a cross-sectional study. Clin Endocrinol. 2009;70:326-30. 
Table 1. Aetiology of congenital hypothyroidism.

\begin{tabular}{|c|c|}
\hline Classification & Aetiology \\
\hline $\begin{array}{l}\text { Permanent Congenital } \\
\text { Hypothyroidism } \\
\text { - Primary }\end{array}$ & $\begin{array}{l}\text { Thyroid dysgenesis (ectopy, athyreosis and } \\
\text { hypoplasia), Thyroid dyshormonogenesis, } \\
\text { Resistance to TSH binding or signalling [7]. }\end{array}$ \\
\hline - Secondary & $\begin{array}{l}\text { - Isolated TSH deficiency and Congenital } \\
\text { hypopituitarism. }\end{array}$ \\
\hline - Peripheral & $\begin{array}{l}\text { - Resistance to thyroid hormone and } \\
\text { Abnormalities of thyroid hormone transport } \\
\text { [2]. }\end{array}$ \\
\hline Syndromic hypothyroidism & $\begin{array}{l}\text { Kocher - Deber - Semilange syndrome, Pendred } \\
\text { syndrome, Choreoathetosis etc [2]. }\end{array}$ \\
\hline $\begin{array}{l}\text { Transient Congenital } \\
\text { Hypothyroidism } \\
\text { - Primary }\end{array}$ & $\begin{array}{l}\text { Endemic iodine deficiency, Prenatal and } \\
\text { postnatal iodine excess, Maternal TSHR } \\
\text { blocking antibodies, Maternal antithyroid } \\
\text { medications, DUOX } 2 \text { mutation, Isolated } \\
\text { hyperthyrotropinemia. }\end{array}$ \\
\hline - Secondary & $\begin{array}{l}\text { - Maternal hyperthyroidism, Prematurity, very } \\
\text { low birth weight, Drugs (Dopamine, steroids), } \\
\text { Transient Hypothyroxinemia [8]. }\end{array}$ \\
\hline
\end{tabular}


Table 2: WHO recommended daily iodine supplementation dosage

\begin{tabular}{|l|l|}
\hline Population Type & Daily intake of iodine supplementation \\
\hline Pregnant women & \multicolumn{1}{|c|}{$\mathbf{\mu g})$} \\
\hline Lactating women & 250 \\
\hline Women of reproductive age (15-49 years) & 150 \\
\hline Children < 2 years & 90 \\
\hline
\end{tabular}




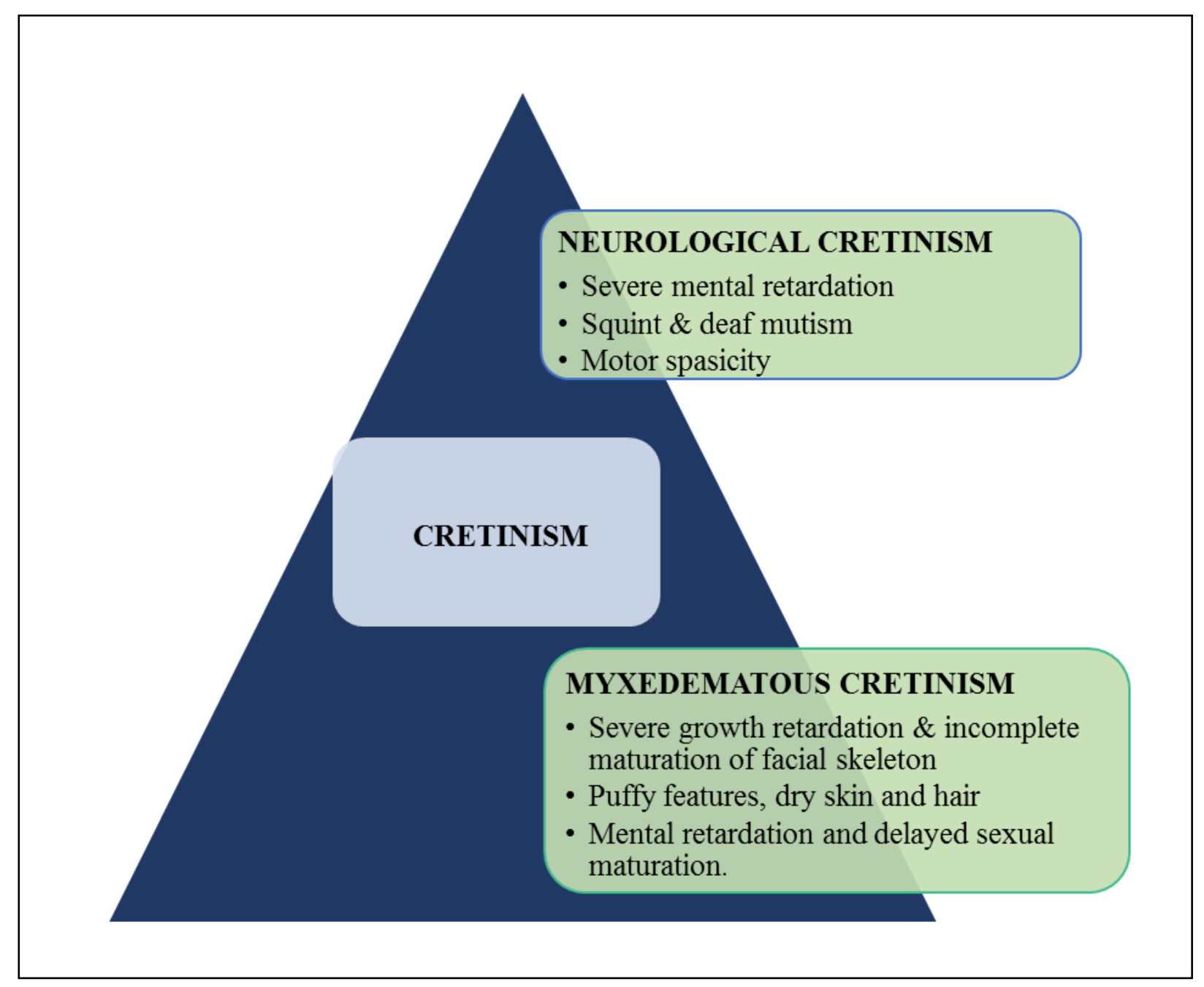

Figure 1 : Types of cretinism and its features 